\title{
Low-Temperature Deposition of Hexagonal Boron Nitride via Sequential Injection of Triethylboron and $\mathrm{N}_{2} / \mathrm{H}_{2}$ Plasma
}

\author{
Ali Haider, ${ }^{\star}{ }^{\S}$ Cagla Ozgit-Akgun, ${ }^{\star}$ Eda Goldenberg, ${ }^{\star}$ Ali Kemal Okyay, ${ }^{\star, \S, \uparrow, \dagger}$ and Necmi Biyikli ${ }^{\ddagger},, \dagger$ \\ ${ }^{*}$ National Nanotechnology Research Center (UNAM), Bilkent University, Bilkent, Ankara 06800, Turkey \\ ${ }^{\S}$ Institute of Materials Science and Nanotechnology, Bilkent University, Bilkent, Ankara 06800, Turkey \\ "Department of Electrical and Electronics Engineering, Bilkent University, Bilkent, Ankara 06800, Turkey
}

\begin{abstract}
Hexagonal boron nitride (hBN) thin films were deposited on silicon and quartz substrates using sequential exposures of triethylboron and $\mathrm{N}_{2} / \mathrm{H}_{2}$ plasma in a hollow-cathode plasmaassisted atomic layer deposition reactor at low temperatures $\left(\leq 450^{\circ} \mathrm{C}\right)$. A non-saturating film deposition rate was observed for substrate temperatures above $250^{\circ} \mathrm{C}$. BN films were characterized for their chemical composition, crystallinity, surface morphology, and optical properties. X-ray photoelectron spectroscopy (XPS) depicted the peaks of boron, nitrogen, carbon, and oxygen at the film surface. $B$ 1s and $N$ 1s high-resolution XPS spectra confirmed the presence of $\mathrm{BN}$ with peaks located at 190.8 and $398.3 \mathrm{eV}$, respectively. As deposited films were polycrystalline, single-phase $\mathrm{hBN}$ irrespective of the deposition temperature. Absorption spectra exhibited an optical band edge at $-5.25 \mathrm{eV}$ and an optical transmittance greater than $\mathbf{9 0 \%}$ in the visible region of the spectrum. Refractive index of the $h B N$ film deposited at $450^{\circ} \mathrm{C}$ was 1.60 at $550 \mathrm{~nm}$, which increased to 1.64 after postdeposition annealing at $800^{\circ} \mathrm{C}$ for $30 \mathrm{~min}$. These results represent the first demonstration of $\mathrm{hBN}$ deposition using low-temperature hollow-cathode plasma-assisted sequential deposition technique.
\end{abstract}

\section{Introduction}

B ORON nitride (BN) and carbon are isoelectronic and isostructural analogues of each other. Similar to carbon materials, BN can exist in the form of different phases such as amorphous $(\mathrm{aBN})$, turbostratic $(\mathrm{tBN})$, hexagonal $(\mathrm{hBN})$, and cubic $(\mathrm{cBN})$. Among the known two-dimensional materials, hBN and graphene are isostructural, yet their physicochemical properties are different. Graphene is the most prominent member of family of layered materials while hBN is an inorganic analogue of graphene. $\mathrm{hBN}$ structure consists of layers of hexagonal sheets, which establishes it as an insulator with a direct band gap of $\sim 5.9 \mathrm{eV}$ in its single crystal form. ${ }^{1-3}$ Boron and nitrogen atoms are bonded together with a strong covalent bond within each $\mathrm{hBN}$ sheet, while different layers of $\mathrm{hBN}$ are bound by van der Waals forces along the $c$-axis at a distance of $6.66 \AA$. Different phases of $\mathrm{BN}$ have been used as powders and coatings in their pure form or as a composite. This versatile material has found applications in metallization, metal industry, high-temperature

G. Brennecka—contributing editor

Manuscript No. 35104. Received June 4, 2014; approved August 6, 2014

Presented in part at the 14th International Conference on Atomic Layer Deposition, Kyoto, Japan, June 16, 2014 (Poster No. 10).

Based in part on the thesis that will be submitted by Ali Haider for the MS degree in materials science and nanotechnology, Bilkent University, Ankara, Turkey, 2014.

${ }^{\dagger}$ Authors to whom correspondence should be addressed. e-mails: aokyay@ee.bilkent.edu.tr and biyikli@unam.bilkent.edu.tr furnaces, cosmetics, and thermal management. $\mathrm{hBN}$ is mainly used for high-temperature crucibles and evaporator boats, and as a lubricant due to its layered structure. hBN offers a significant advantage over conventional lubricants due to its high-temperature stability and high oxidation resistance. ${ }^{1-8}$ The interest in the fabrication of thin films and coatings of either hBN or $\mathrm{cBN}$ stems from their high structural strength, high-temperature stability, high oxidation resistance, low surface energy, and high thermal conductivity, which already led to numerous technological applications. Application of $\mathrm{hBN}$ as a dielectric layer for graphene-based electronics has been reported. ${ }^{2,9}$ UV lasing has also been demonstrated with the production of high quality hBN flakes by Kubota et al. Their high quality hBN flakes paved the way to demonstrate applications of hBN in UV light emitting diodes. ${ }^{4,5}$

Producing high quality $\mathrm{BN}$ thin films has proven to be very challenging. BN films deposited by physical vapor deposition (PVD) suffer from poor adhesion and cracking, ${ }^{10,11}$ whereas BN films deposited by chemical vapor deposition (CVD) might result in a mixture of $\mathrm{hBN}$, tBN, and $c B N$ phases. ${ }^{12-14}$ Boron/nitrogen precursors used to obtain $\mathrm{hBN}$ films through CVD are reported as $\mathrm{BF}_{3} / \mathrm{NH}_{3}, \mathrm{BCl}_{3} / \mathrm{NH}_{3}$, and $\mathrm{B}_{2} \mathrm{H}_{6} / \mathrm{NH}_{3}{ }^{15-17}$ Postdeposition annealing is routinely utilized for structural enhancement, surface roughness control, and intrinsic stress elimination in thin films. Structural ordering of hBN has been accomplished using proper annealing. ${ }^{3}$ Researchers have also employed atomic layer deposition (ALD) technique for $\mathrm{BN}$ thin film deposition to obtain highly conformal and uniform BN films with simple thickness control. BN films obtained via ALD were either aBN or tBN, in which $\mathrm{BBr}_{3} / \mathrm{NH}_{3}$ and $\mathrm{BCl}_{3} / \mathrm{NH}_{3}$ were utilized as boron/nitrogen precursors, respectively. ${ }^{18-20}$ Substrate temperatures for self-limiting growth was reported to be in the range of $250^{\circ} \mathrm{C}-750^{\circ} \mathrm{C}$. However, due to the nature of these halide precursors, the byproducts of surface reactions are hazardous and corrosive. ${ }^{21,22} \mathrm{hBN}$ deposition with borazine, which is a nonhalide precursor, has been reported to result in a monolayer limited deposition under ultra high vacuum conditions on transition-metal surfaces..$^{23,24}$ The deposition terminated or became very slow after the formation of an initial monolayer of $\mathrm{BN}$, therefore deposition was believed to be surface inhibited due to the inert nature of boron nitride.

For modern electronic applications, it is imperative to obtain high quality $\mathrm{BN}$ films on large area substrates with a controlled thickness to fulfill the entire spectrum of hBN applications. Also, a facile method is necessary to obtain $\mathrm{BN}$ films at low temperatures compliant with the standards in terms of having nontoxic byproducts. In this work, we demonstrate for the first time the controlled deposition of hBN films with the use of a hollow-cathode plasma source integrated ALD reactor, which has recently been used to deposit III-nitride thin films. ${ }^{25}$ Depositions are carried out at low substrate temperatures using sequential injection of 
nonhalide triethylboron (TEB) and $\mathrm{N}_{2} / \mathrm{H}_{2}$ plasma as the boron and nitrogen precursors, respectively. The deposition process parameters such as pulse length of TEB and substrate temperature, as well as the influence of postdeposition annealing are studied. Thin film materials characterization studies are carried out to reveal the structural and optical properties of hBN films.

\section{Experimental Procedure}

\section{(1). Film Deposition}

$\mathrm{BN}$ thin films were deposited on precleaned substrates at temperatures ranging from $250^{\circ} \mathrm{C}$ to $450^{\circ} \mathrm{C}$. Depositions were carried out in a Fiji F200-LL ALD reactor (Cambridge Nanotech Inc., Cambridge, MA), which is equipped with a stainless steel hollow cathode plasma source (Meaglow Ltd., Thunder Bay, ON, Canada). The base pressure of the system was 150 mTorr. TEB and $\mathrm{N}_{2} / \mathrm{H}_{2}$ were carried from separate lines using 30 and $100 \mathrm{sccm} \mathrm{Ar}$, respectively. $\mathrm{N}_{2} / \mathrm{H}_{2}$ gas flow rates and plasma power were constant in all experiment as $50 / 50 \mathrm{sccm}$ and $300 \mathrm{~W}$, respectively. The system was purged for $20 \mathrm{~s}$ after each precursor exposure. Before depositions, $\mathrm{Si}$ (100) and double side polished quartz substrates were cleaned by ultrasonic stirring in 2-propanol, acetone, methanol, and DI-water, respectively. Solvent cleaned silicon substrates were finally immersed into dilute HF solution for $\sim 1 \mathrm{~min}$, then rinsed with DI-water and dried with $\mathrm{N}_{2}$.

\section{(2) Film Characterization}

Grazing-incidence X-ray diffraction (GIXRD) patterns were recorded in an X'Pert PRO MRD diffractometer (PANalytical B.V., Almelo, Netherlands) using $\mathrm{Cu} K_{\alpha}$ radiation. Data were obtained within the 2 Theta range of $20^{\circ}-80^{\circ}$ by the summation of ten scans, which were performed using $0.1^{\circ}$ step size and $10 \mathrm{~s}$ counting time. Interplanar spacing $\left(d_{h k l}\right)$ values for the (010) and (002) planes were calculated from the corresponding peak positions using the well-known Bragg's law. Lattice parameters $a$ and $c$ were roughly calculated by substituting $d_{010}$ and $d_{002}$ values, respectively, in Eq. (1), which relates the interplanar spacing $\left(d_{h k l}\right)$, miller indices $(h k l)$ and lattice parameters $(a$ and $c$ ) for hexagonal crystals.

$$
\frac{1}{d^{2}}=\frac{4}{3}\left(\frac{h^{2}+h k+k^{2}}{a^{2}}\right)+\frac{l^{2}}{c^{2}}
$$

By neglecting instrumental broadening and assuming that the observed broadening is only related to the size effect, crystallite size values for the as-deposited and annealed films were estimated from the (010) reflection using Eq. (2), the well-known Scherrer formula ${ }^{26}$

$$
d=\frac{0.9 \lambda}{B \cos \theta}
$$

where $\lambda, B$ and $\theta$ are the wavelength of the radiation used $\left(\mathrm{Cu} K_{\alpha}=1.5418 \AA\right.$ ), broadening (FWHM) and Bragg diffraction angle of the selected reflection, respectively.

Elemental composition and chemical bonding states of the films were determined by X-ray photoelectron spectroscopy (XPS) using Thermo Scientific K-Alpha spectrometer (Thermo Fisher Scientific, Waltham, MA) with a monochromatized Al $K_{\alpha} \mathrm{X}$-ray source. Sputter depth profiling was performed with a beam of $\mathrm{Ar}$ ions having an acceleration voltage and spot size of $1 \mathrm{kV}$ and $400 \mu \mathrm{m}$, respectively.

Scanning electron microscope (SEM) studies were carried out using Quanta 200 FEG SEM (FEI, Hillsboro, OR). Samples were coated with $\sim 5 \mathrm{~nm} \mathrm{Au} / \mathrm{Pd}$ alloy prior to SEM imaging. Surface morphologies of the BN thin films were revealed using an atomic force microscope (AFM) (XE-100E,
PSIA, Suwon, Korea), operated in the contact mode. Tecnai G2 F30 transmission electron microscope (TEM) (FEI, Hillsboro, OR) was utilized for the high-resolution (HR) imaging of the BN thin film sample, which was capped with a $20 \mathrm{~nm}$ AlN layer prior to TEM sample preparation. AIN was deposited at $200^{\circ} \mathrm{C}$ using hollow-cathode plasma-assisted ALD, details of which are given elsewhere. ${ }^{23}$ TEM sample was prepared by a Nova 600i Nanolab focused ion beam (FIB) system (FEI, Hillsboro, OR) at an acceleration voltage of $30 \mathrm{kV}$ using various beam currents ranging from $50 \mathrm{pA}$ to $21 \mathrm{nA}$. Damage layer was removed by FIB milling at a beam voltage of $5 \mathrm{kV}$. Elemental mapping was performed in TEM, using an energy dispersive X-ray spectrometer (EDX). An accelerating voltage of $300 \mathrm{keV}$, beam current of $1 \mathrm{nA}$, detector energy resolution of $134 \mathrm{eV}$, and detector angle of $14.6^{\circ}$ are the important parameters of EDX that were utilized for elemental mapping.

Spectral transmission measurements were performed with a UV-VIS spectrophotometer (HR4000CG-UV-NIR, Ocean Optics Inc., Dunedin, FL) in the wavelength range of 220 $1000 \mathrm{~nm}$ relative to air, and the optical constants of the films were determined using a variable angle spectroscopic ellipsometer (V-VASE, J.A. Woollam Co. Inc., Lincoln, NE) which is equipped with rotating analyzer and xenon light source. The ellipsometric spectra were collected at three angles of incidence $\left(65^{\circ}, 70^{\circ}\right.$, and $\left.75^{\circ}\right)$ to yield adequate sensitivity over the full spectral range. Optical constants and film thicknesses were extracted by fitting the spectroscopic ellipsometry data. The numerical iteration was performed to minimize the mean-square error function using WVASE32 software (J.A. Woollam Co. Inc., Lincoln, NE). The homogeneous Tauc-Lorentz (TL) function was used as an oscillator. In addition, data fitting was improved using the Bruggeman effective medium approximation at the film-air interface assuming 50\% film and $50 \%$ voids. The absorption coefficient,

$$
\alpha(\lambda)=\frac{4 \pi k(\lambda)}{\lambda}
$$

was calculated from the $k(\lambda)$ values determined from the ellipsometry data. Optical band gap $\left(E_{\mathrm{g}}\right)$ is expressed by the following equation for direct band gap materials, ${ }^{27}$ which can be analytically extracted via extrapolation of the linear part of the absorption spectrum to $(\alpha E)^{2}=0$.

$$
\alpha E=A\left(E-E_{\mathrm{g}}\right)^{1 / 2}
$$

The estimated film thickness values were also confirmed by cross-sectional TEM. Growth per cycle (GPC) values was calculated by dividing film thicknesses to the number of growth cycles.

The effect of annealing on the optical properties of $\mathrm{BN}$ films was investigated by annealing the $\mathrm{BN}$ films at $800^{\circ} \mathrm{C}$ for $30 \mathrm{~min}$ in $\mathrm{N}_{2}$ environment. Postdeposition annealing was performed using a rapid thermal annealing system (Unitherm RTA SRO-704, ATV Technologie GmbH, Vaterstetten, Germany). $\mathrm{N}_{2}$ flow and heating rate were $200 \mathrm{sccm}$ and $10^{\circ} \mathrm{C} / \mathrm{s}$, respectively. Samples were taken out of the system after they cooled down to $80^{\circ} \mathrm{C}$.

\section{Results and Discussion}

Deposition experiments of $\mathrm{BN}$ were carried out within the temperature range of $250^{\circ} \mathrm{C}-450^{\circ} \mathrm{C}$ by the sequential injection of TEB and $\mathrm{N}_{2} / \mathrm{H}_{2}$ plasma, where one cycle consisted of TEB pulse $/ 20 \mathrm{~s}$ Ar purge $/ 40 \mathrm{~s}, 50 / 50 \mathrm{sccm} \mathrm{N}_{2} / \mathrm{H}_{2}$ plasma $(300 \mathrm{~W}) / 20 \mathrm{~s}$ Ar purge. Dependency of GPC of BN on TEB pulse length at different temperatures is given in Fig. 1. At $350^{\circ} \mathrm{C}$, GPC was $0.10 \AA$ for $0.06 \mathrm{~s}$ of TEB pulse length, 


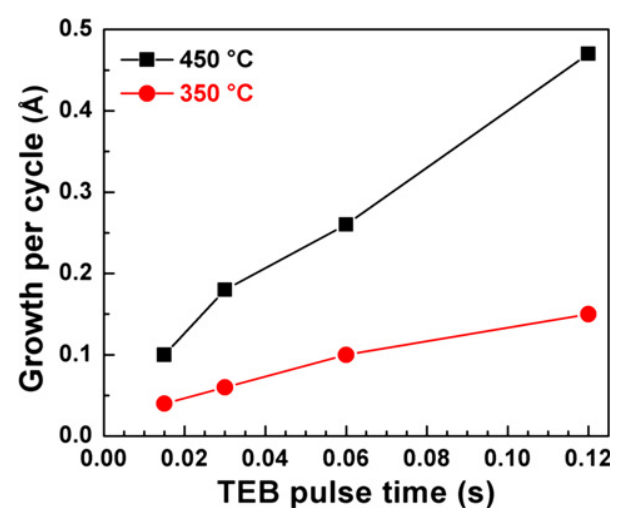

Fig. 1. Effect of TEB dose on GPC at different temperatures. $\mathrm{N}_{2}$ and $\mathrm{H}_{2}$ flow rates, plasma power and purge time were kept constant.

which went up to $0.15 \AA$ after increasing the TEB pulse length to $0.12 \mathrm{~s}$. Reasonable GPC values were achieved at substrate temperatures higher than $350^{\circ} \mathrm{C}$, whereas surfaceinhibited growth was observed at $250^{\circ} \mathrm{C}$. At $450^{\circ} \mathrm{C}, \mathrm{GPC}$ was $0.26 \AA$ for $0.06 \mathrm{~s}$ of TEB pulse length, which increased to $0.47 \AA$ for $0.12 \mathrm{~s}$ of TEB pulse length. GPC increases almost linearly with increasing TEB pulse length at $350^{\circ} \mathrm{C}$ and $450^{\circ} \mathrm{C}$ with no saturation, which points towards the possibility of thermal decomposition of TEB at temperatures higher than $250^{\circ} \mathrm{C}$. Thus, no self-limiting growth behavior has been observed, indicating a CVD-like deposition mode with substrate temperatures above the possible ALD window. To further investigate this issue and understand the decomposition temperature, controlled experiments, where Si substrates have been exposed to 100 TEB pulses, were performed within the $250^{\circ} \mathrm{C}-450^{\circ} \mathrm{C}$ range and the resulting surfaces were analyzed with XPS. High-resolution B 1s scan is given in Fig. 2, which has been analyzed for the possible bonding schemes of boron. B 1s HR-XPS spectrum gathered from the Si (100) surface exposed to 100 cycles of TEB at $350^{\circ} \mathrm{C}$ was fitted by single peak with a binding energy of $189.3 \mathrm{eV}$, which indicates the presence of boron suboxide $\left(\mathrm{B}_{6} \mathrm{O}\right) .{ }^{28}$ While $\mathrm{B}$ 1s HR-XPS spectrum gathered from the $\mathrm{Si}$ (100) surface exposed to 100 cycles of TEB at $450^{\circ} \mathrm{C}$ was fitted by two subpeaks with binding energies of 187.5 and $192.1 \mathrm{eV}$, which correspond to $\mathrm{B}-\mathrm{B}^{29}$ and $\mathrm{B}-\mathrm{O}^{30}$ bonds of boronoxide $\left(\mathrm{B}_{2} \mathrm{O}_{3}\right)$, respectively. On the other hand, for the $\mathrm{Si}$ substrate exposed to TEB precursor at $250^{\circ} \mathrm{C}$, only $\mathrm{B}-\mathrm{C}$ bond ${ }^{31}$ is detected. TEB is an alkyl precursor which contains direct metal to carbon bond. B-C bond detection confirms that TEB is stable at $250^{\circ} \mathrm{C}$ (i.e., no decomposition) and decomposition initiates at temperatures higher than $250^{\circ} \mathrm{C}$.

The crystal structures of the as-deposited and annealed BN films were characterized by GIXRD. Figure 3(a) shows the GIXRD patterns of $\sim 47$ and $\sim 15 \mathrm{~nm}$ thick BN films deposited on $\mathrm{Si}(100)$ substrates at $450^{\circ} \mathrm{C}$ and $350^{\circ} \mathrm{C}$, respectively. The results revealed that $\mathrm{BN}$ films were polycrystalline with hexagonal structure (ICDD reference code: 98-002-7986). As seen from Fig. 3(a), the (010) reflection of the hexagonal phase is dominant, while the other two reflections of hexagonal phase, i.e., (002) and (111), are weakly pronounced. The relatively broad diffraction peaks obtained suggest that BN films are composed of small crystallites. From $2 \theta$ position of the (002) reflection, the lattice parameter $c$ was calculated for the film deposited at $450^{\circ} \mathrm{C}$. Interplanar spacing $\left(d_{h k l}\right)$ of $(002)$ planes was calculated from Bragg's law and it was inserted in Eq. (1) to obtain the $c$-axis lattice parameter, which came out to be $0.71 \mathrm{~nm}$. This value is fairly close to $0.67 \mathrm{~nm}$, which is the ideal value for hBN. ${ }^{32}$ Previous ALD studies of BN growth, however, reported $c$-axis lattice parameters above $0.70 \mathrm{~nm}$, which deviate from the ideal value of $\mathrm{hBN}$ and attributed to the existence of turbostratic BN phase. ${ }^{18,20}$ Since $(010)$ peak in the GIXRD pattern [Fig. 3(a)] is well-defined, $a$-axis lattice

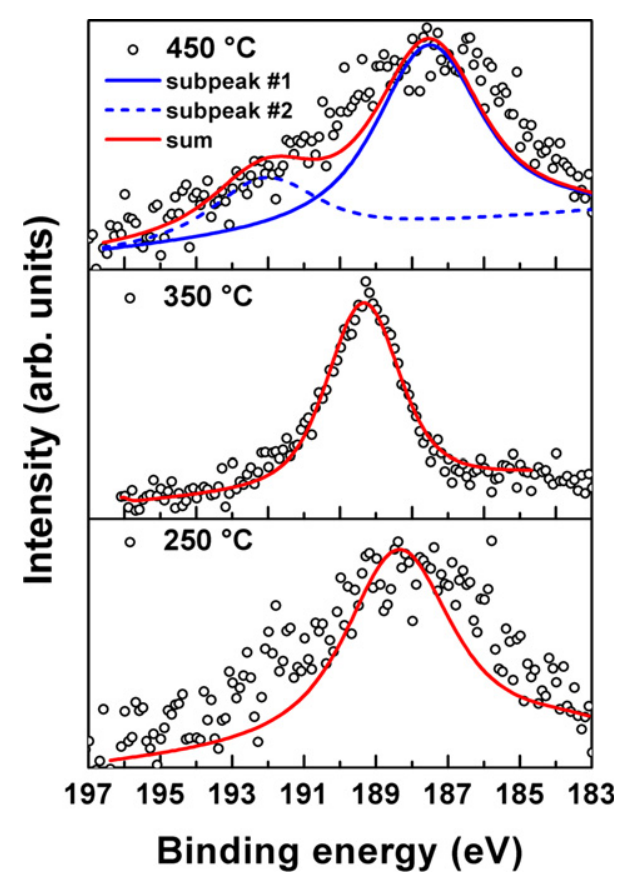

Fig. 2. High-resolution B 1s scans obtained from Si surfaces, which have been exposed to 100 pulses of TEB at different temperatures.

parameter estimation would be more accurate as compared to $c$-axis lattice parameter estimation. From $2 \theta$ position of the (010) reflection, the lattice parameter $a$ was calculated for the film deposited at $450^{\circ} \mathrm{C}$. Interplanar spacing $\left(d_{h k l}\right)$ for the $(010)$ plane was calculated from Bragg's law and it was inserted in Eq. (1) to obtain the $a$-axis lattice parameter, which came out to be $0.25 \mathrm{~nm}$. This value matches well with the ideal value $(0.25 \mathrm{~nm})$ of $a$-axis lattice parameter for hBN. ${ }^{32}$ This shows the superiority of HCPA-ALD over thermal ALD for obtaining a predominantly hexagonal phase in BN films.

Figure 3(b) shows a comparison of the GIXRD patterns of the as-deposited and annealed BN thin films deposited at $450^{\circ} \mathrm{C}$. One can conclude that the intensity of (010) reflection increases and the full width at half maximum (FWHM) becomes slightly narrower after the postdeposition annealing. FWHM of the $\mathrm{hBN}$ film deposited at $450^{\circ} \mathrm{C}$ was measured as 123 arc-minutes, which decreased to 106 arc-minutes after annealing. By neglecting instrumental broadening and assuming that the observed broadening is only related to the size effect, crystallite size values for the as-deposited and annealed films were estimated from corresponding (002) reflections using the well-known Scherrer formula. ${ }^{26}$ The crystallite size was found to be $4.4 \mathrm{~nm}$ for the film deposited at $450^{\circ} \mathrm{C}$, which slightly increased to $4.7 \mathrm{~nm}$ after annealing process at $800^{\circ} \mathrm{C}$ for $30 \mathrm{~min}$.

To investigate the elemental compositions, chemical bonding states and impurity contents of the films, XPS was conducted on hBN films deposited on Si (100) substrates. Survey scans indicated the presence of boron, carbon, nitrogen, and oxygen with $\mathrm{B} 1 \mathrm{~s}, \mathrm{C} 1 \mathrm{~s}, \mathrm{~N} 1 \mathrm{~s}$, and $\mathrm{O}$ 1s peaks located at $190.6,284.6,398.0$, and $532.6 \mathrm{eV}$, respectively. Table I provides a comparison of the elemental compositions and the corresponding $\mathrm{B} / \mathrm{N}$ ratios for as-deposited and annealed $\mathrm{BN}$ films. It illustrates that films are almost stoichiometric with $\mathrm{B} / \mathrm{N}$ ratios of $\sim 1.05$ to 1.12 . An increase of $2-3$ at. $\%$ was observed in the oxygen concentrations of films after annealing, which might be due to initiation of oxidation at the surfaces of BN films. Figure 4(a) is the compositional depth profile of $\mathrm{hBN}$ thin film, which indicates the variation in atomic concentrations of boron, nitrogen, carbon, and oxygen along the etching direction from the air $/ \mathrm{hBN}$ interface towards the $\mathrm{hBN} / \mathrm{Si}$ (100) interface. Boron and nitrogen 

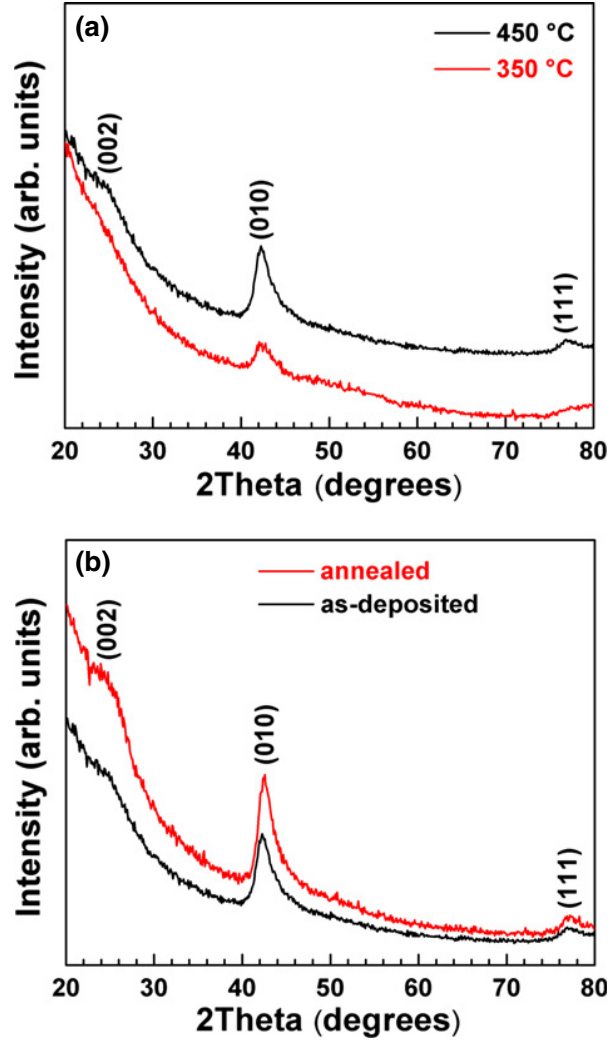

Fig. 3. (a) GIXRD patterns of $\sim 47$ and $\sim 15 \mathrm{~nm}$ thick $B N$ films deposited on $\mathrm{Si}(100)$ substrates at $450^{\circ} \mathrm{C}$ and $350^{\circ} \mathrm{C}$, respectively. (b) GIXRD pattern of the $\sim 47 \mathrm{~nm}$ thick BN film deposited on $\mathrm{Si}(100)$ substrate at $450^{\circ} \mathrm{C}$ : annealed versus as-deposited.

Table I. Elemental Compositions and B/N Ratios Obtained from XPS Survey Spectra

\begin{tabular}{lccccc}
\hline & \multicolumn{4}{c}{ Elemental composition (at.\%) } & \\
\cline { 2 - 5 } Deposition temperature & $\mathrm{B}$ & $\mathrm{N}$ & $\mathrm{O}$ & $\mathrm{C}$ & \multirow{2}{*}{ B/N ratio } \\
\hline $350^{\circ} \mathrm{C}$ (as-deposited) & 42.70 & 40.81 & 4.55 & 5.55 & 1.05 \\
$350^{\circ} \mathrm{C}$ (annealed) & 46.27 & 42.15 & 7.29 & 4.29 & 1.09 \\
$450^{\circ} \mathrm{C}$ (as-deposited) & 44.06 & 38.47 & 4.46 & 6.05 & 1.14 \\
$450^{\circ} \mathrm{C}$ (annealed) & 47.99 & 42.85 & 6.18 & 2.98 & 1.12 \\
\hline
\end{tabular}

Data were collected from bulk of the films.

atomic concentrations were found to be constant in the bulk film. 15 at. $\%$ oxygen was detected at the film surface, which decreased to $\sim 2$ at. $\%$ in the bulk of the film, while carbon content was also around 2 at. $\%$ in the bulk of the BN film. The carbon impurity contents in the films might be originating from the ethyl groups of TEB, which did not react with the $\mathrm{N}_{2} / \mathrm{H}_{2}$ plasma and therefore remained in the growing film.

The high-resolution scans of $\mathrm{B} 1 \mathrm{~s}$ and $\mathrm{N}$ 1s are given in Figs. 4(b) and (c), respectively, which refer to the bulk film $\left(t_{\text {etch }}=720 \mathrm{~s}\right)$. FWHM and asymmetry of the peaks suggest that there are more than one type of bonding scheme for boron and nitrogen. The high-resolution XPS spectra were therefore analyzed to inspect the possible bonding schemes of the deposited hBN. B 1s HR-XPS spectrum gathered from the surface of a $\sim 47 \mathrm{~nm}$ thick $\mathrm{BN}$ sample deposited on $\mathrm{Si}$ (100) substrate was fitted by two subpeaks with binding energies of 190.8 and $189.0 \mathrm{eV}$. In literature it has been reported that the B1s HR spectrum exhibits binding energies of $190.8^{33}$ and $189^{34,35}$ for BN and B-C bond in boroncarbonitride (BCN) films, respectively. Therefore, the subpeak detected at $190.8 \mathrm{eV}$ can be safely attributed to the B-N
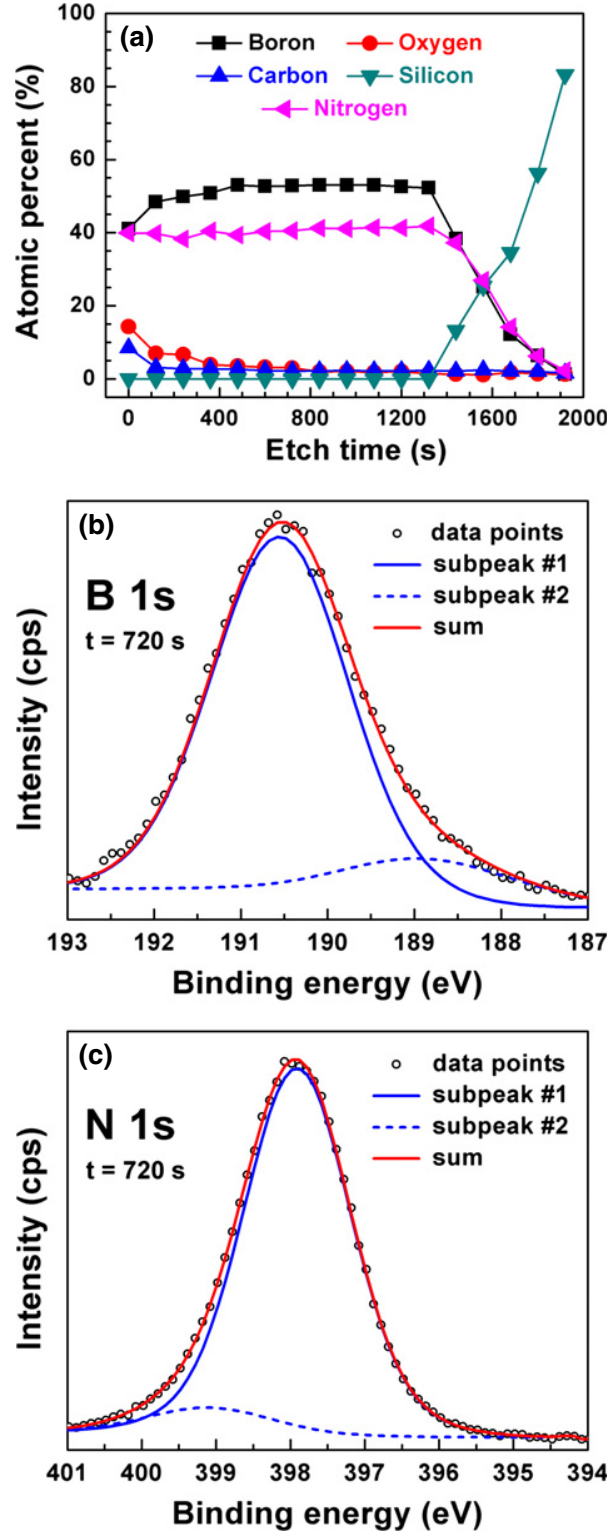

Fig. 4. (a) Compositional depth profile of $\sim 47 \mathrm{~nm}$ thick $\mathrm{BN}$ thin film deposited on $\mathrm{Si}(100)$ at $450^{\circ} \mathrm{C}$. (b, c) High-resolution B 1s and $\mathrm{N} 1 \mathrm{~s}$ scans of the same sample. Data were collected after $720 \mathrm{~s}$ of $\mathrm{Ar}$ ion etching.

bond, while the peak at $189.0 \mathrm{eV}$ possibly indicates the presence of B-C bonding state of BCN. N 1s HR-XPS spectrum given in Fig. 4(c) was fitted by two subpeaks located at 398.3 and $399.1 \mathrm{eV}$. In literature it has been reported that $\mathrm{N} 1 \mathrm{~s}$ HR spectrum exhibits a binding energy of $399 \mathrm{eV}^{34,35}$ for $\mathrm{N}-\mathrm{C}$ bond in boroncarbonitride $(\mathrm{BCN})$ films. The subpeak at $398.3 \mathrm{eV}^{36}$ confirms the presence of $\mathrm{BN}$, while the subpeak at $399.1 \mathrm{eV}$ again indicates the formation of $\mathrm{BCN}$.

Figure 5(a) shows plan-view SEM image of $\mathrm{hBN}$ film deposited on $\mathrm{Si}$ (100) substrate at $450^{\circ} \mathrm{C}$, while Fig. 5(b) shows the SEM image of the same sample after it has been annealed at $800^{\circ} \mathrm{C}$ for $30 \mathrm{~min}$. SEM analysis of the as-deposited sample reveals that the surface of the $\mathrm{hBN}$ thin film sample is not uniform with a rough, compact, and threedimensional (3D) curly surface morphology. It shows a branching feature with peculiar 3D nano-scale structures. SEM image of annealed sample [Fig. 5(b)], on the other hand, reveals that branched $3 \mathrm{D}$ nanostructures have mostly coalesced to form a more continuous and larger-grained but still nonuniform film surface. The presence of this branching feature is not well understood yet; however, one possible 

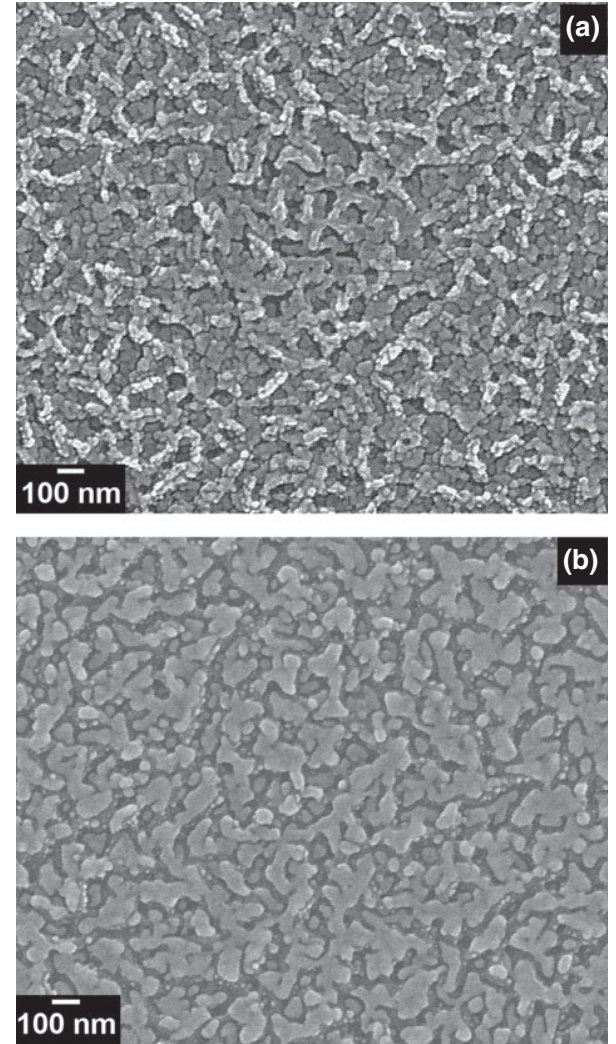

Fig. 5. SEM images of $\sim 47 \mathrm{~nm}$ thick $\mathrm{BN}$ thin film deposited on $\mathrm{Si}$ (100) substrate at $450^{\circ} \mathrm{C}$ : (a) as-deposited, and (b) annealed.

mechanism is that abundant deposition vapor in CVD mode might have created new deposition steps on the preceding BN nanosheets, which could have resulted in the outgrowth of this branching structure. At some later stage during the deposition, the branched nanostructure might have terminated upon colliding with other branches, resulting in a highly 3D nanostructured surface. ${ }^{37}$

Surface morphologies of the hBN thin films were further examined by AFM. Figures 6(a) and (b) show the surface scans of the $\sim 47 \mathrm{~nm}$ thick BN thin film sample before and after annealing at $800^{\circ} \mathrm{C}$ for $30 \mathrm{~min}$, respectively. Root mean square (rms) roughness of the as-deposited film was measured as $0.70 \mathrm{~nm}$ from a $1 \mu \mathrm{m} \times 1 \mu \mathrm{m}$ scan area. Film roughness increased to $0.83 \mathrm{~nm}$ after annealing.

TEM experiments were carried out on a BN sample, which was prepared separately by the deposition of 2000 cycles on a Si (100) substrate at $450^{\circ} \mathrm{C}$ with $0.12 \mathrm{~s}$ of TEB pulse length. Before TEM sample preparation, an AIN capping layer was deposited on top of the $\mathrm{BN}$ layer to preserve its crystal structure by providing a barrier layer against the damage of highenergy Ga ions of the FIB system. The average thickness of $\mathrm{BN}$ was measured as $\sim 90 \mathrm{~nm}$ from cross-sectional TEM measurements, which is in close agreement with the data obtained from spectroscopic ellipsometery. Figure 7(a) is the cross-sectional TEM image of $\mathrm{BN}$ thin film. It can be observed that the interface between $\mathrm{AlN}$ and $\mathrm{BN}$ is not distinct, which confirms the nonuniform surface morphology of $\mathrm{BN}$ layer. Figure 7(b) shows the HR-TEM image indicating the polycrystalline structure and lattice fringes of hBN film. It is seen that hBN is composed of nanometer-sized crystallites.

Figure 8(a) shows EDX elemental maps of $\mathrm{B}, \mathrm{Al}$, and $\mathrm{Si}$ obtained from the AlN-capped BN thin film sample deposited on $\mathrm{Si}(100)$ at $450^{\circ} \mathrm{C}$. The elemental distribution is clarified by selecting a cross-sectional portion in the specimen and rastering the electron beam point by point over the selected portion of interest. The colorized maps show strong
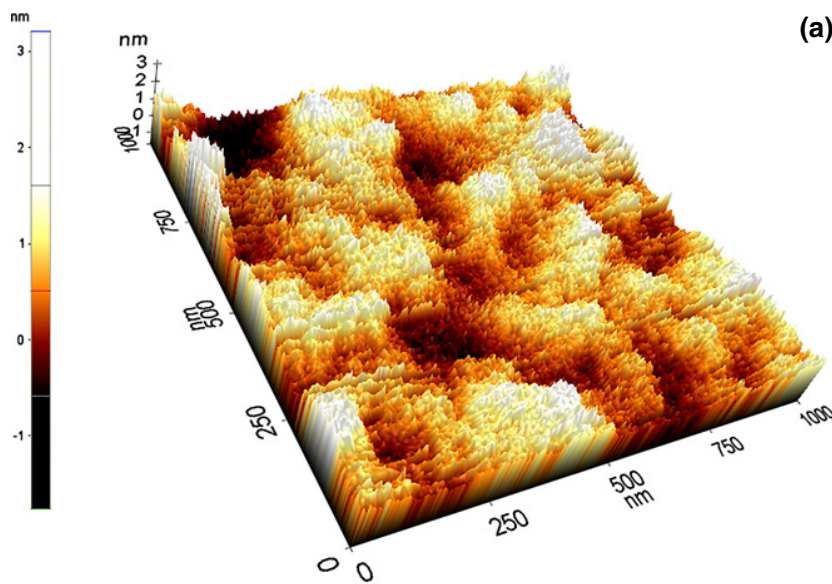

(a)

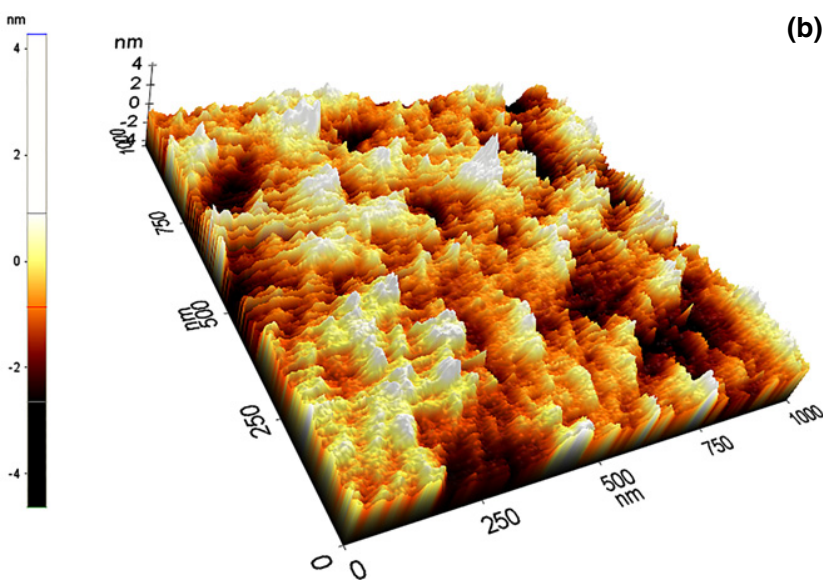

Fig. 6. (a) Surface morphologies of $\sim 47 \mathrm{~nm}$ thick $\mathrm{BN}$ thin film deposited on $\mathrm{Si}$ (100) substrate at $450^{\circ} \mathrm{C}$ : (a) as-deposited, and (b) annealed.

contrast among $\mathrm{B}, \mathrm{Al}$, and $\mathrm{Si}$, and they reveal the elemental distribution along the scanned area. The interface between $\mathrm{Al}$ and $\mathrm{B}$ is fuzzy, which confirms the intermixing of $\mathrm{Al}$ and $\mathrm{B}$ at the interface due to the nonuniform surface morphology of $\mathrm{BN}$, which was noticed by high-magnification SEM and HR-TEM imaging as well. Figure 8(b) shows the selected area electron-diffraction (SAED) pattern of the same AlN/ $\mathrm{BN}$ sample. Polycrystalline diffraction rings can be seen from this pattern. The analysis of SAED pattern has been summarized in Table II, which compares measured and theoretical values for h-BN and h-AlN crystallographic planes. Reflections from (010) and (111) crystallographic planes are detected for h-BN, which agree well with the data obtained from GIXRD measurements; while (100) and (102) reflections of the h-AlN phase are detected from the capping layer. Theoretical and experimental interplanar spacing $\left(d_{h k l}\right)$ values are fairly close to each other for the corresponding crystallographic planes of h-BN and h-AlN.

Normal incidence transmission spectra of $\mathrm{BN}$ thin film samples deposited on double side polished quartz substrates in the UV-VIS and NIR regions are presented in Fig. 9. The average transmittance was measured to be in the $91 \%-93 \%$ range within the visible spectrum, very close to bare quartz transmission performance, which indicates that films are almost fully transparent in this wavelength region. Significant decrease in transmission was observed at UV wavelengths less than $280 \mathrm{~nm}$, which is believed to be caused by the main band gap absorption. Optical band gap value was estimated from absorption edge of the films using Eq. (3). The value of $E_{\mathrm{g}}$ was calculated from the inset of Fig. 9, which shows $(\alpha h v)^{2}$ vs. $h v$ plot. The optical band gap was 

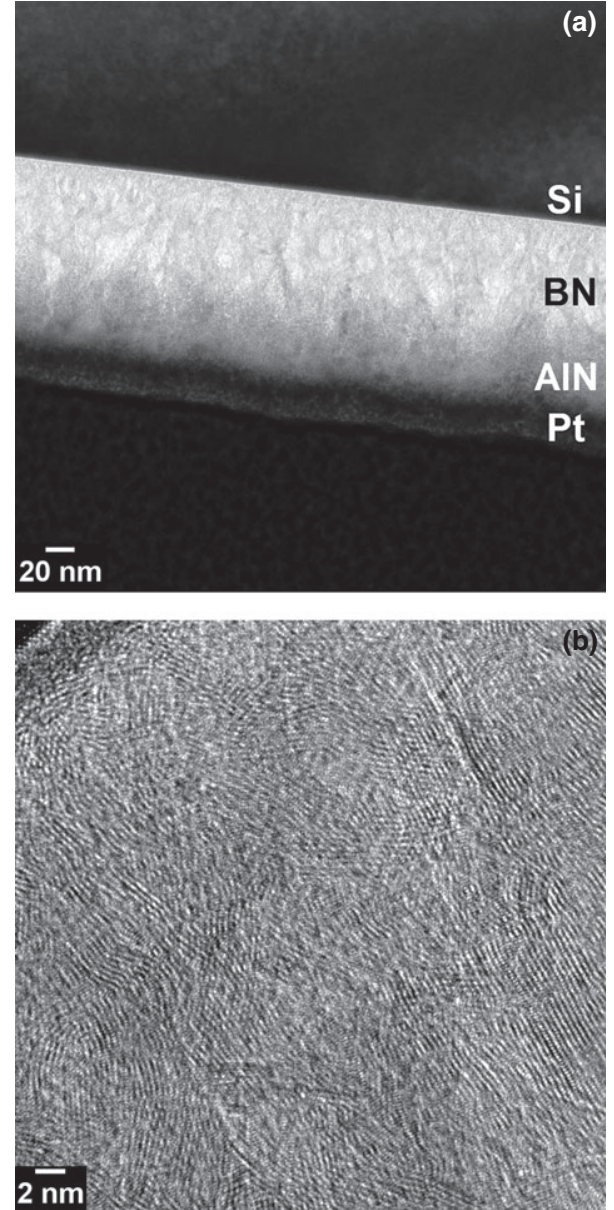

Fig. 7. (a) Cross-sectional TEM image of AlN-capped $\sim 90 \mathrm{~nm}$ thick BN thin film deposited at $450^{\circ} \mathrm{C}$ on $\mathrm{Si}$ (100) substrate. (b) Cross-sectional HR-TEM image of the same sample.
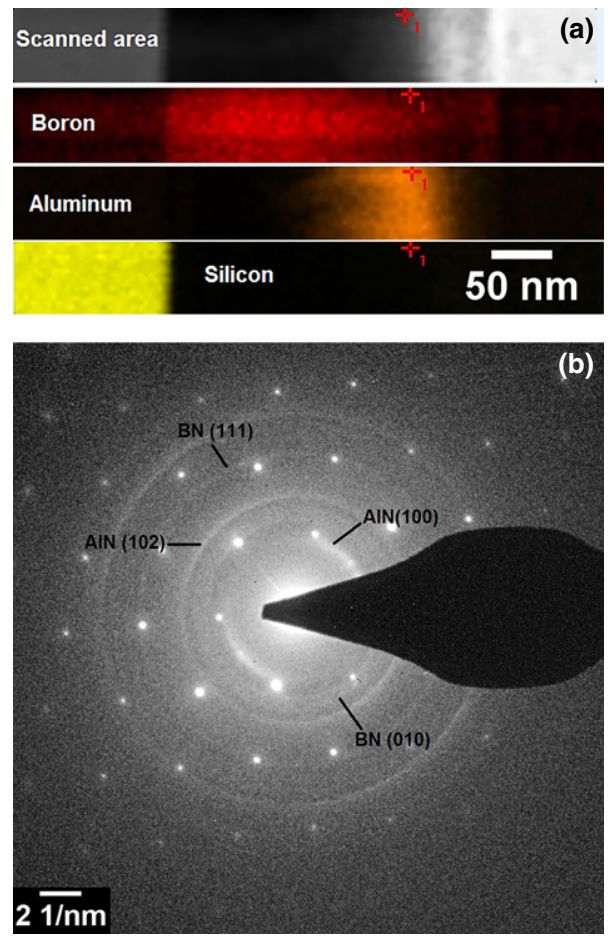

Fig. 8. (a) Elemental map of the AlN-capped $\sim 90 \mathrm{~nm}$ thick BN thin film deposited on $\mathrm{Si}(100)$ substrate at $450^{\circ} \mathrm{C}$. (b) SAED pattern of the same sample.
Table II. SAED Pattern Analysis of AIN-Capped $\sim 90 \mathrm{~nm}$

Thick BN Thin Film Deposited on Si (100) Substrate at $450^{\circ} \mathrm{C}$ : Comparison Between Measured and Theoretical Values of Interplanar Spacing $\left(d_{h k l}\right)$ with Corresponding Crystallographic Planes

\begin{tabular}{|c|c|c|c|c|}
\hline \multirow{2}{*}{$\begin{array}{l}\text { Diameter } \\
\left(\mathrm{nm}^{-1}\right)\end{array}$} & \multicolumn{2}{|c|}{$\begin{array}{c}\text { Interplanar spacing, } d_{h k l} \\
(\AA)\end{array}$} & \multirow{2}{*}{$\begin{array}{c}\text { Corresponding } \\
\text { material }\end{array}$} & \multirow{2}{*}{$\begin{array}{c}\text { Corresponding } \\
\text { plane, }(h k l)\end{array}$} \\
\hline & Calculated & Theoretical & & \\
\hline 7.358 & 2.7181 & $2.6950^{\dagger}$ & AlN & 100 \\
\hline 9.180 & 2.1786 & $2.1737^{\star}$ & $\mathrm{BN}$ & 010 \\
\hline 11.056 & 1.8089 & $1.8290^{\dagger}$ & AlN & 102 \\
\hline 16.127 & 1.2401 & $1.2334^{\star}$ & $\mathrm{BN}$ & 111 \\
\hline
\end{tabular}

${ }^{\dagger}$ Hexagonal AlN, ICDD reference code: 00-025-1133.

${ }^{*}$ Hexagonal BN, ICDD reference code: 98-002-7986.
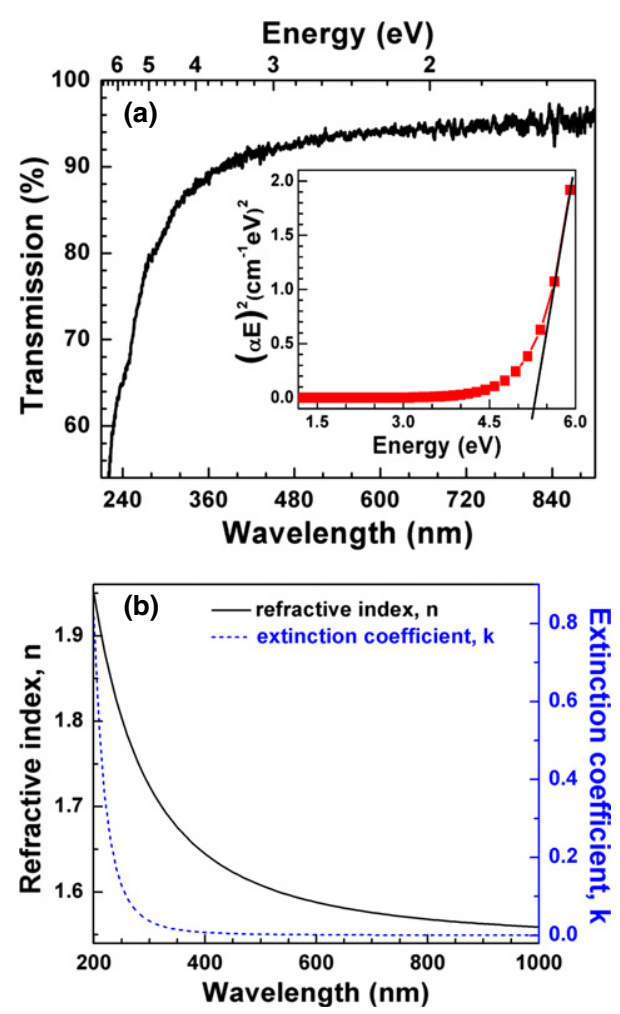

Fig. 9. (a) Optical transmission, and (inset) absorption spectra of the $\sim 47 \mathrm{~nm}$ thick BN thin film deposited on double side polished quartz. (b) Optical constants (refractive index and extinction coefficient) of the same sample.

determined by extrapolating the straight line segment of the plot to abscissa as described earlier, and found to be $\sim 5.25 \mathrm{eV}$. No change in optical bang gap is observed for the annealed counterpart. The existence of a single slope in the graph is an indication that $\mathrm{hBN}$ features direct optical transitions. The value of $E_{\mathrm{g}}$ obtained in our work matches well with the $E_{\mathrm{g}}$ value measured for polycrystalline $\mathrm{hBN}$ films by Hoffman et al. ${ }^{38}$ However, there is huge discrepancy in measured values of $E_{\mathrm{g}}$. In literature, $E_{\mathrm{g}}$ value of $\mathrm{hBN}$ is largely dispersed in the range of $4.0-7.1 \mathrm{eV}$, which is explained by the differences in experimental methods used and quality of deposited hBN. ${ }^{39}$ Initially, single crystal hBN was reported as a direct band gap material with an $E_{\mathrm{g}}$ value of $5.9 \mathrm{eV}$, but recently for polycrystalline $\mathrm{hBN}$, it was demonstrated to be an indirect band gap material with an $E_{\mathrm{g}}$ value of $6.5 \mathrm{eV} .^{1,40}$ In view of numerous different reports, more experimental results regarding optical band gap of hBN are required. 
Table III. Refractive Indices of the hBN Films Deposited on Si (100) Substrates at Different Temperatures

\begin{tabular}{lc}
\hline Deposition temperature & Refractive index, $n$ at $550 \mathrm{~nm}$ \\
\hline $350^{\circ} \mathrm{C}$ (as-deposited) & 1.55 \\
$350^{\circ} \mathrm{C}$ (annealed) & 1.61 \\
$450^{\circ} \mathrm{C}$ (as-deposited) & 1.60 \\
$450^{\circ} \mathrm{C}$ (annealed) & 1.64 \\
\hline
\end{tabular}

Optical constants of the BN film were obtained by modeling the ellipsometric spectra in the wavelength range of 200-1000 nm. Figure 9(b) shows the variation in the refractive index as a function of incident photon wavelength. The refractive index decreases from 1.65 to 1.56 in the visible spectrum. Similar results have been reported in the literature for polycrystalline hBN films. ${ }^{41,42}$ Furthermore, the extinction coefficient $(k)$ decreased swiftly within the UV range and became almost zero at higher wavelengths, indicating the near-ideal transparency of the films in the visible spectrum. Refractive index value at $550 \mathrm{~nm}$ for the films deposited at $350^{\circ} \mathrm{C}$ and $450^{\circ} \mathrm{C}$ are summarized in Table III. Refractive index value at $550 \mathrm{~nm}$ was measured as 1.55 for the $\mathrm{BN}$ film deposited at $350^{\circ} \mathrm{C}$, which increased to 1.61 after annealing the film. While, for the films deposited at $450^{\circ} \mathrm{C}$, refractive index values at $550 \mathrm{~nm}$ increased from 1.60 to 1.64 after annealing treatment. This slight increase might be attributed to structural enhancement (i.e., increase in grain size and/or film densification) upon annealing.

\section{Summary and Conclusions}

hBN thin films were deposited on silicon and quartz substrates using TEB and $\mathrm{N}_{2} / \mathrm{H}_{2}$ plasma in an hollow cathode plasma-assisted atomic layer deposition (HCPA-ALD) reactor. Appreciable GPC values were only observed at substrate temperatures above $350^{\circ} \mathrm{C}$. At $350^{\circ} \mathrm{C}$, GPC was $0.15 \AA$ for TEB pulse length of $0.12 \mathrm{~s}$, while it was $0.47 \AA$ at $450^{\circ} \mathrm{C}$ for the same TEB pulse length. GPC did not saturate with increasing TEB doses, indicating the thermal decomposition of the boron precursor. $\mathrm{BN}$ thin films synthesized in CVD regime at $350^{\circ} \mathrm{C}$ and $450^{\circ} \mathrm{C}$ were polycrystalline with hexagonal structure as determined by GIXRD and HR-TEM. B 1s and $\mathrm{N}$ 1s HR-XPS scans further confirmed the presence of BN with peaks located at 190.8 and $398.3 \mathrm{eV}$, respectively. Rms surface roughness of the as-deposited $\mathrm{BN}$ thin film at $450^{\circ} \mathrm{C}$ was measured as $0.70 \mathrm{~nm}$ from a $1 \mu \mathrm{m} \times 1 \mu \mathrm{m}$ scan area. Films exhibited an optical band edge at $\sim 5.25 \mathrm{eV}$ and high transparency $(>90 \%)$ in the visible region of the spectrum. Postdeposition annealing resulted in a slight improvement in crystallinity and led to an increase in crystallite size, refractive index and surface roughness of $\mathrm{BN}$ thin films deposited at $450^{\circ} \mathrm{C}$. This study represents the first demonstration of controlled deposition of hBN films within a HCPAALD reactor at relatively low substrate temperatures using sequential injection of nonhalide triethylboron (TEB) and $\mathrm{N}_{2} / \mathrm{H}_{2}$ plasma as the boron and nitrogen precursors, respectively.

\section{Acknowledgments}

This work was performed at Bilkent University - National Nanotechnology Research Center (UNAM) supported by the Ministry of Development of Turkey through the National Nanotechnology Research Center Project. This work was supported by the Scientific and Technological Research Council of Turkey (TUBITAK), grant nos. 109E044, 112M004, 112E052, 112M482, and $113 \mathrm{M} 815$. N.B and A.K.O acknowledge support from FP-7 Marie Curie International Re-integration Grant (grant nos. PIRG05-GA-2009249196 and PIRG04-GA-2008-239444). E. Goldenberg acknowledges TUBITAK-BIDEB 2232 scholarship. Authors would like to acknowledge M. Guler from UNAM for TEM sample preparation and HR-TEM measurements. A. Haider acknowledges Higher Education Commission of Pakistan
(HEC) for Human resource development (HRD) fellowship for MS leading to $\mathrm{PhD}$.

\section{References}

${ }^{1}$ K. Watanabe, T. Taniguchi, and H. Kanda, "Direct-Bandgap Properties and Evidence for Ultraviolet Lasing of Hexagonal Boron Ntride Single Crystal," Nat. Mater., 3 [6] 404-9 (2004).

${ }^{2}$ C. R. Dean, A. F. Young, I. Meric, C. Lee, L. Wang, S. Sorgenfrei, K. Watanabe, T. Taniguchi, P. Kim, K. L. Shepar, and J. Hone, "Boron Nitride Substrates for High-Quality Graphene Electronics," Nat. Nanotechnol., 5 [10] 722-6 (2010).

${ }^{3}$ R. T. Paine and C. K. Narula, "Synthetic Routes to Boron Nitride," Chem. Rev., 90 [1] 73-91 (1990).

${ }^{4}$ K. Watanabe, T. Taniguchi, T. Niiyama, K. Miya, and M. Taniguchi, "Far-Ultraviolet Plane-Emission Handheld Device Based on Hexagonal Boron Nitride," Nat. Photon., 3 [10] 591-4 (2009).

${ }^{5}$ Y. Kubota, K. Watanabe, O. Tsuda, and T. Taniguchi, "Deep Ultraviolet Light-Emitting Hexagonal Boron Nitride Synthesized at Atmospheric Pressure," Science, 317 [5840] 932-4 (2007).

${ }^{6}$ R. W. Trice and J. W. Halloran, "Elevated-Temperature Mechanical Properties of Silicon Nitride/Boron Nitride Fibrous Monolithic Ceramics," J. Am. Ceram. Soc., 83 [2] 311-6 (2000).

R. W. Trice and J. W. Halloran, "Investigation of the Physical and Mechanical Properties of Hot-Pressed Boron Nitride/Oxide Ceramic Composites," J. Am. Ceram. Soc., 82 [9] 2563-5 (1999).

${ }^{8}$ D. H. Choa, J. S. Kima, S. H. Kwona, C. Lee, and Y. Z. Lee, "Evaluation of Hexagonal Boron Nitride Nano-Sheets as a Lubricant Additive in Water" Wear, 302 [1-2] 981-6 (2013).

${ }^{9}$ K. K. Kim, A. Hsu, X. Jia, S. M. Kim, Y. Shi, M. Dresselhaus, T. Palacios, and J. Kong, "Synthesis and Characterization of Hexagonal Boron Nitride Film as a Dielectric Layer for Graphene Devices," ACS Nano., 6 [10] 8583-90 (2012).

${ }^{10}$ D. J. Kester and R. Messier, "Phase Control of Cubic Boron Nitride Thin Films," J. Appl. Phys., 72 [2] 504-13 (1992).

${ }^{11}$ M. Goto, A. Kasahara, M. Tosa, T. Kimura, and K. Yoshihara, "Characteristics of Thin Films of Hexagonal Boron Nitride Mixed With Copper Controlled by a Magnetron Co-Sputtering Deposition Technique," App. Surf. Sci., $185[3-4]$ 172-6 (2002).

${ }^{12}$ P. C. Huang and M. S. Wong, "Nanostructures of Mixed-Phase Boron Nitride via Biased Microwave Plasma-Assisted CVD," Vaccum, 100, 66-70 (2014).

${ }^{13}$ W. A. Yarbrough, "Current Research Problems and Opportunities in the Vapor Phase Synthesis of Diamond and Cubic Boron Nitride," J. Vac. Sci. Technol., A, 9 [3] 1145-52 (1991).

${ }^{14}$ A. Bartl, S. Bohr, R. Haubner, and B. Lux, "A Comparison of LowPressure CVD Synthesis of Diamond and c-BN," Int. J. Ref. Met. H, 14 [1-3] 145-57 (1996).

${ }^{15}$ H. O. Pierson, "Boron Nitride Composites By Chemical Vapor Deposition," J. Compos. Mater., 9 [3] 228-40 (1975).

${ }^{16}$ A. S. Rozenberg, Yu. A. Sinenko, and N. V. Chukanov, "Regularities of Pyrolytic Boron Nitride Coating Formation on a Graphite Matrix," J. Mater. Sci., 28 [20] 5528-33 (1993).

${ }^{17} \mathrm{~S}$. Middleman, "The Role of Gas-Phase Reactions in Boron Nitride Growth by Chemical Vapor Deposition," S. Mater. Sci. Eng. A, 163 [1] 135-40 (1993).

${ }^{18}$ B. Marlid, M. Ottosson, U. Pettersson, K. Larsson, and J. O. Carlsson, "Atomic Layer Deposition of BN Thin Films," Thin Solid Films, 402 [1-2] 167-71 (2002).

${ }^{19}$ J. D. Ferguson, A. W. Weimer, and S. M. George, "Atomic Layer Deposition of Boron Nitride Using Sequential Exposures of $\mathrm{BCl}_{3}$ and $\mathrm{NH}_{3}$," Thin Solid Films, 413 [1-2] 16-25 (2002).

${ }^{20}$ J. Olander, L. M. Ottosson, P. Heszler, J. O. Carlsson, and K. M. E. Larsson, "Laser Assisted Atomic Layer Deposition of Boron Nitride Thin Film," Chem. Vap. Deposition, 11 [6-7] 330-7 (2005).

${ }^{21}$ J. L. Huang, C. H. Pan, and D. F. Lii, "Investigation of the BN Films Prepared by Low Pressure Chemical Vapor Deposition" Surf. Coat. Technol., 122 [2-3] 166-75 (1999).

${ }^{22}$ F. Rebillat, A. Guette, and C. R. Brosse, "Chemical and Mechanical Alterations of SiC Nicalon Fibers Properties During the CVD/CVI Process for Boron Nitride," Acta Mater., 47 [5] 1685-96 (1999).

${ }^{23}$ W. Auwarter, T. J. Kreutz, T. Greber, and J. Osterwalder, "XPD and STM Investigation of Hexagonal Boron Nitride on Ni(111)," Surf. Sci., 429 [1-3] 229-36 (1999).

${ }^{24}$ P. Sutter, J. Lahiri, P. Albrecht, and E. Sutter, "Chemical Vapor Deposition and Etching of High Quality Monolayer Hexagonal Boron Nitride Films," ACS Nano, 5 [9] 7303-9 (2011).

${ }^{25}$ C. Ozgit-Akgun, E. Goldenberg, N. Biyikli, and A. K. Okyay, "Hollow Cathode Plasma-Assisted Atomic Layer Deposition of Crystalline AlN, GaN and $\mathrm{Al}_{\mathrm{x}} \mathrm{Ga}_{1-\mathrm{x}} \mathrm{N}$ Thin Films at Low Temperatures," J. Mater. Chem. C, 2 [12] 2123-36 (2014).

${ }^{26}$ B. D. Cullity, Elements of X-ray Diffraction; pp. 99. Addison-Wesley Reading, Massachusetts, 1970

${ }^{27}$ E. Rosencher, Optoelectronics; pp. 304. Cambridge university press, Newyork, 2002.

${ }^{28}$ M. Belyansky, M. Trenary, and C. Ellison, "Boron Chemical Shifts in B 6 O," Surf. Sci. Spectra, 3 [2] 147-50 (1994).

${ }^{29}$ D. N. Hendrickson, J. M. Hollander, and W. L. Jolly, "Core-Electron Binding Energies for Compounds of Boron, Carbon, and Chromium," Inorg. Chem., 9 [3] 612-5 (1970). 
${ }^{30}$ Z. F. Song, S. Z. Ye, Z. Y. Chen, L. Song, and J. Shen, "Study on Boron-Film Thermal Neutron Converter Prepared by Pulsed Laser Deposition," Appl. Radiat. Isotopes, 69 [2] 443-7 (2011).

${ }^{31}$ L. G. Jacobsohn, R. K. Schulze, M. E. H. Maia da Costa, and M. Nastasi, "X-ray Photoelectron Spectroscopy Investigation of Boron Carbide Films Deposited by Sputtering," Surf. Sci., 572 [2-3] 418-24 (2004).

${ }^{32}$ R. W. Lynch and H. G. Drickamer, "Effect of High Pressure on the Lattice Parameters of Diamond, Graphite, and Hexagonal Boron Nitride," J. Chem. Phys., 44 [1] 181-3 (1966).

${ }^{33}$ M. Das, A. K. Basua, S. Ghataka, and A. G. Joshib, "Carbothermal Synthesis of Boron Nitride Coating on PAN Carbon Fiber," J. Eur. Ceram. Soc., 29 [10] 2129-34 (2009).

${ }^{34}$ M. A. Mannan, M. Nagano, K. Shigezumi, T. Kida, N. Hirao, and Y. Baba, "Characterization of Boron Carbonitride (BCN) Thin Films Deposited by Radiofrequency and Microwave Plasma Enhanced Chemical Vapor Deposition," Am. J. Appl. Sci., 5 [6] 736-41 (2007).

${ }^{35}$ T. Thamm, D. Wett, W. Bohne, E. Strub, J. Rohrich, R. Szargan, G. Marx, and W. A. Goedel, "Investigations on PECVD Boron Carbonitride Layers by Means of ERDA, XPS and Nano-Indentation Measurements," Microchim. Acta, 156 [1-2] 53-6 (2007).
${ }^{36}$ X. Gouin, P. Grange, L. Bois, P. L'Haridon, and Y. Laurent, "Chracterization Process of the Nitridation Process of Boric Acid," J. Alloys Compd., 224 [1] 22-8 (1995).

${ }^{37}$ A. Pakdel, Y. Bando, D. Shtansky, and D. Golberg, "Non Wetting and Optical Properties of BN Nanosheet Films," Surf. Innov., 1 [1] 32-9 (2012).

${ }^{38}$ D. M. Hoffman, G. L. Doll, and P. C. Eklund, "Optical Properties of Pyrolytic Boron Nitride in the Energy Range 0.05-10 eV," Phys. Rev. B, 30 [10] 6051-6 (1984).

${ }^{39}$ V. L. Solozhenko, A. G. Lazarenko, J. P. Petitet, and A. V. Kanaev, "Bandgap Energy of Graphite-Like Hexagonal Boron Nitride," J. Phys. Chem. Solids., 62 [7] 1331-4 (2001).

${ }^{40}$ L. Museur, E. Feldbach, and A. Kanaev, "Defect-Related Photoluminescence of Hexagonal Boron Nitride," Phys. Rev. B, 78 [15] 1552041, 8pp (2008).

${ }^{41}$ A. Abdellaoui, A. Bath, B. Bouchikhi, and O. Baehr, "Structure and Optical Properties of Boron Nitride Thin Films Prepared by PECVD," Mater. Sci. Eng., B, 47 [3] 257-62 (1997).

${ }^{42}$ T. A. Anutgan, M. Anutgan, I. Atilgan, and B. Katircioglu, "Stability and Degradation of Plasma Deposited Boron Nitride Thin Films in Ambient Atmosphere," Thin Solid Films, 518 [1] 419-25 (2009). 